\title{
The Influence of Number of CFRP Layers on the CFRP/Concrete Bond Behavior
}

\author{
Wasim S. Barham, Yasmeen T. Obeidat, Ammar I. AL-Maabreh
}

\begin{abstract}
The influence of number of CFRP sheet layers on bond strength between CFRP sheet and concrete was investigated by conducting double shear type pullout test. A total of eighteen concrete prisms were examined with different number of CFRP layer and maximum aggregate size. One, two and three layers of CFRP sheet were used. The experimental results indicate that the number of layers affect the bond strength. When the number of layer increases the bond strength increases beyond a certain value. Therefore, the number of layer is another factor that causes the CFRP sheets not to be fully utilized.
\end{abstract}

Keywords- CFRP layers, bond strength, bond behavior, concrete, slippage

\section{Introduction}

In the world of construction, reinforced concrete is the most widely used due to its durability, strength and fire resistance. However, recently the wolds' concrete structure is in need for repair or retrofitting. The need for repair is due to several reasons such as environmental harshness, deterioration of concrete, corrosion of the steel, and damaged caused by earthquake load. In selecting material for repairing solution, it is preferable and recommended using lightweight materials with high durability, strength, and high corrosion resistant. Therefore, retrofitting or strengthening structural elements to resist high load design or to correct damage in structural elements using high performance material, fiber reinforced polymer (FRP), has been successfully established.

The FRP may be attached to its substrate as externally bonded adhesively, sheet or plate, or as a thin, narrow near surface mounted (NSM) strip being inserted and bonded into a groove on the member. Even though externally bonded FRP has proven an excellent material for repairing and strengthening of concrete members, de-bonding failure is a major drawback that externally bonded FRP repairing materials suffer from. This failure is a premature brittle failure and limited the utilization of FRP material, plate or sheet, therefore its full strength is never reached. De-bonding failure happens because of a high stress concentration at the concreteFRP bond interface.

Wasim S. Barham - Associate Professor

Jordan University of Science and Technology

Jordan

Yasmeen T. Obeidat - Assistant Professor

Jordan University of Science and Technology

Jordan

Ammar I. AL-Maabreh - MS student

Jordan University of Science and Technology

Jordan
Different tests are available to evaluate the bond behavior between FRP and concrete such as direct or pure shear, double shear test, and flexure [1] and [2]. Over the last decade, a good deal of research has been conducted to study the efficiency of the use of FRP sheets in strengthening various structural elements. Several studies were conducted to examine the effects of bond length. The research found that when the bond length increases the bond length increases beyond a certain extent [3, 4, and 5]. Another studied the bond width of FRP sheets [6] and it was found that the smaller the sheet width gives the higher average shear bond strength. Dia et al. [7] reported that ductility can be improved by using low elastic moduli FRP which lead to higher bond strength.

In this study, experimental tests were performed to understand the behavior of the bond between CFRP and concrete, furthermore, the effects of length of FRP on the bond strength of the concrete-FRP interface was examined.

\section{Test Setup and Material Properties}

Eighteen concrete prism of (150x 150x200 mm) were prepared and casted using normal concrete. Type 1 ordinary Portland cement, water, coarse limestone of $19 \mathrm{~mm}$ or $25 \mathrm{~mm}$ maximum aggregate size (Dmax), fine aggregate and silica sand were used for concrete mixture. A super-plasticizer was added to the mixture to achieve the target workability. Mixes proportion are listed in Table 1. Concrete mixes were designed according to the ACI mix design procedure to obtain compressive strength of $30 \mathrm{MPa}$ and a slump of $80 \mathrm{~mm}$.

Table 1. Concrete Proportions of Each Mix

\begin{tabular}{|c|c|c|c|c|c|}
\hline \multirow{2}{*}{ Material } & \multicolumn{5}{|c|}{ Weight kg/m3 } \\
\cline { 2 - 6 } & Cement & $\begin{array}{c}\text { Coarse } \\
\text { Aggregate }\end{array}$ & $\begin{array}{c}\text { Fine } \\
\text { Aggregate }\end{array}$ & $\begin{array}{c}\text { Silica } \\
\text { Sand }\end{array}$ & $\begin{array}{c}\text { Wate } \\
\boldsymbol{r}\end{array}$ \\
\hline Mix\#1 & 428.6 & 1005 & 463.8 & 309. & 229 \\
$($ Dmsx=19mm) & & & & 2 & \\
\hline $\begin{array}{c}\text { Mix\#2 } \\
(\text { Dmax=25 mm) }\end{array}$ & 445.25 & 976 & 461.4 & 307. & $\begin{array}{c}251 . \\
5\end{array}$ \\
\hline
\end{tabular}

The prisms were designed to fit for pull out test, therefore the concrete mixture was casted in wooden molds with inner dimensions of $(150 \times 150 \times 200) \mathrm{mm}$. Concrete was placed in the molds in three layers; each compacted using a vibrating table, before the concrete blocks surface was finished by a trowel to smooth the surface. The specimens were de-molded after 24 hours then emerged in curing tank for another 28 days at standard conditions to gain its full strength. The average compressive strength of the concrete with cylinder $100 \times 200$ $\mathrm{mm}$ was $30 \mathrm{MPa}$ at 28 days. 
Unidirectional CFRP sheet was used in this study. The mechanical properties of CFRP for elastic modulus and tensile strength are $230 \mathrm{GPa}$ and $4900 \mathrm{MPa}$, respectively. To ensure good bond, the prism surface was prepared and grinded to obtain rough surface using diamond grinding disk and then was cleaned using vacuum cleaner to remove the dust. Finally, two carbon fiber reinforced polymer (CFRP) sheets externally bonded to two opposite sides of the concrete prisms using epoxy adhesive, "Fig. 1". Thereafter, the prism cured for 7 days at standard conditions. The width of CFRP sheet was 120 $\mathrm{mm}$ with layer thickness $0.17 \mathrm{~mm}$. The tested concrete prisms were divided into two groups. Each group represents different maximum aggregate size and consisted of nine prisms. The groups were designated by letters and numerals representing concrete compressive strength, maximum aggregate size, bonded length of CFRP sheet, bonded width of FRP sheet and number of CFRP layers, respectively. Table 2 illustrates the characteristics and designation of the specimens studied in this paper.

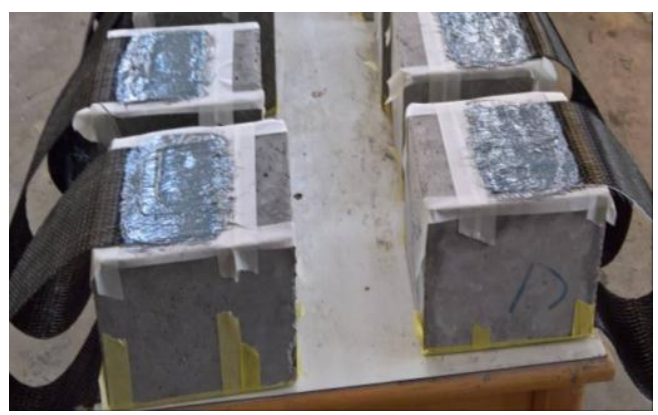

Figure 1. Strengthened prisms

Table 2. Specimen Designation

\begin{tabular}{|c|c|c|c|c|c|c|}
\hline Designation & $\begin{array}{c}\text { \# of } \\
\text { cubes }\end{array}$ & $\begin{array}{c}\text { CS } \\
\text { (MP) }\end{array}$ & $\begin{array}{c}\text { MAS } \\
\text { (mm) }\end{array}$ & $\begin{array}{c}\text { BL } \\
\text { (cm) }\end{array}$ & $\begin{array}{c}\text { BW } \\
\text { (cm) }\end{array}$ & NL \\
\hline P30-25-10-12-1L & 3 & 30 & 25 & 10 & 12 & 1 \\
\hline P30-25-10-12-2L & 3 & 30 & 25 & 10 & 12 & 2 \\
\hline P30-25-10-12-3L & 3 & 30 & 25 & 10 & 12 & 3 \\
\hline P30-19-10-12-1L & 3 & 30 & 19 & 10 & 12 & 1 \\
\hline P30-19-10-12-2L & 3 & 30 & 19 & 10 & 12 & 2 \\
\hline P30-19-10-12-3L & 3 & 30 & 19 & 10 & 12 & 3 \\
\hline
\end{tabular}

Double shear testing was carried out where the pull out force is applied as shown in the test setup "Fig. 2". The setup of this test consists of a U-shaped steel arm pinned to an aluminum cylinder. The aluminum cylinder is pulled to generate tensile force in order to cause de-bonding between CFRP sheet and concrete surface, [8]. Two linear variable differential transducers (LVDTs) were used to record the slip at CFRP sheets. Both of the two LVDTs were placed in the same manner, it was mounted at each side of the concrete- CFRP sheet by a piece of glass pre-glued to sheet surface, while its node in contact with another piece of glass pre-glued to concrete surface. This manner was used to make sure that the relative displacement between CFRP and concrete was monitor. The load measurements were collected using a data acquisition system.
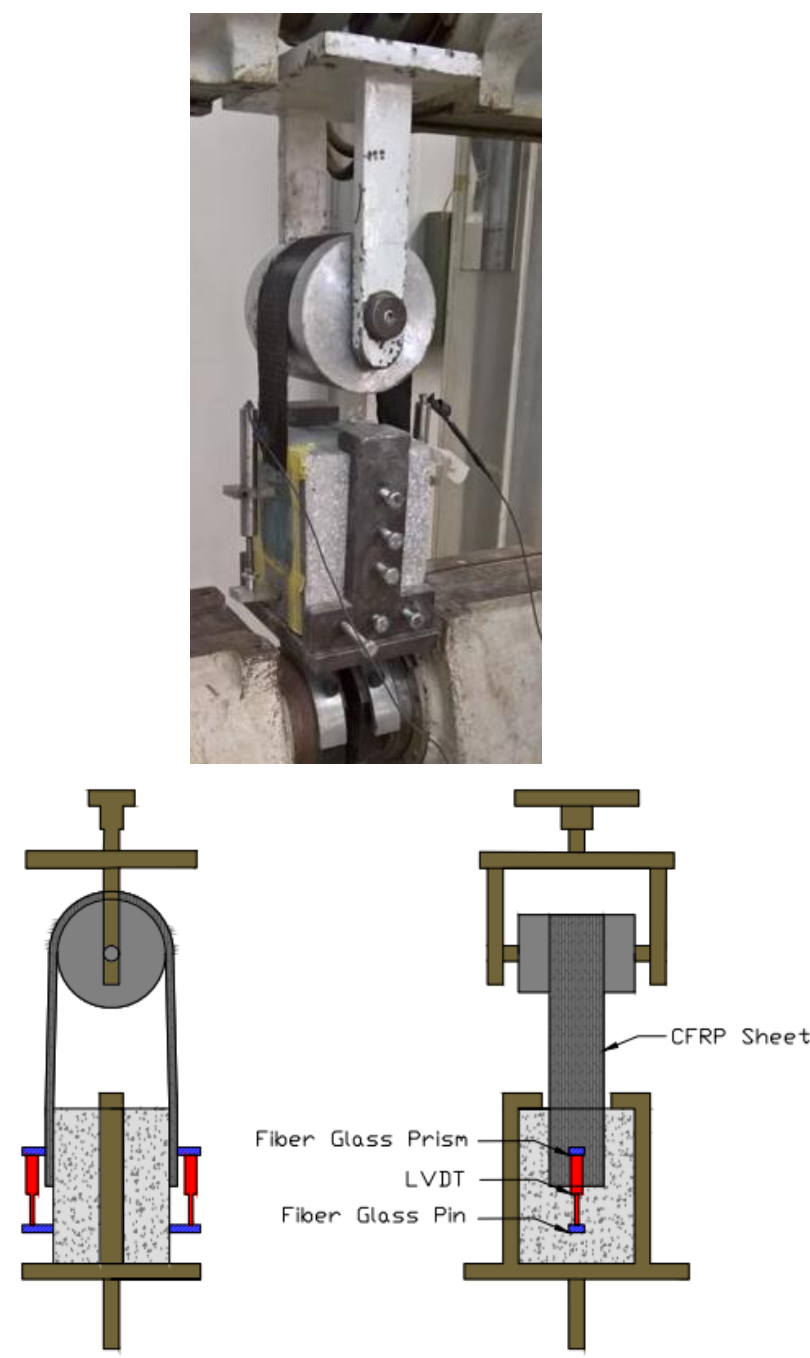

Figure 2. Test Setup

\section{Experimental results and discussion}

Fig. 3 shows the bond strength versus slip behavior for all specimens. The bond length, the bond width and concrete compressive strength were kept constant at $10 \mathrm{~cm}, 12 \mathrm{~cm}$ and $30 \mathrm{MPa}$, respectively. It is clear from all Figures that the bond strength-slippage curves follow the same trend. Curves can be divided into two zones. The first zone is almost linear with significant increase in bond stress under small slippage values. This zone starts from the beginning of the loading process until the beginning of de-bonding. The second zone is almost constant with significant increase in slippage with no or small increase in bond stress; it started from the initiation of the debonding until failure. The initial stiffness of the CFRP concrete increases with the increase in number of CFRP sheet layers. 
The results in Table 3, and Fig. 3 show that significant enhancement in the bond strength was achieved by increasing the number of layers from 1 layer to 2 layers. However, the bond strength do not increase after a certain number of layers; the bond strength decreases when three layers of CFRP used for both maximum aggregate size.

Table 3. Testing Results

\begin{tabular}{|c|c|}
\hline Designation & UL(KN) \\
\hline P30-25-10-12-1L & 16.10 \\
\hline P30-25-10-12-2L & 24.72 \\
\hline P30-25-10-12-3L & 21.48 \\
\hline P30-19-10-12-1L & 18.00 \\
\hline P30-19-10-12-2L & 25.80 \\
\hline P30-19-10-12-3L & 21.00 \\
\hline
\end{tabular}

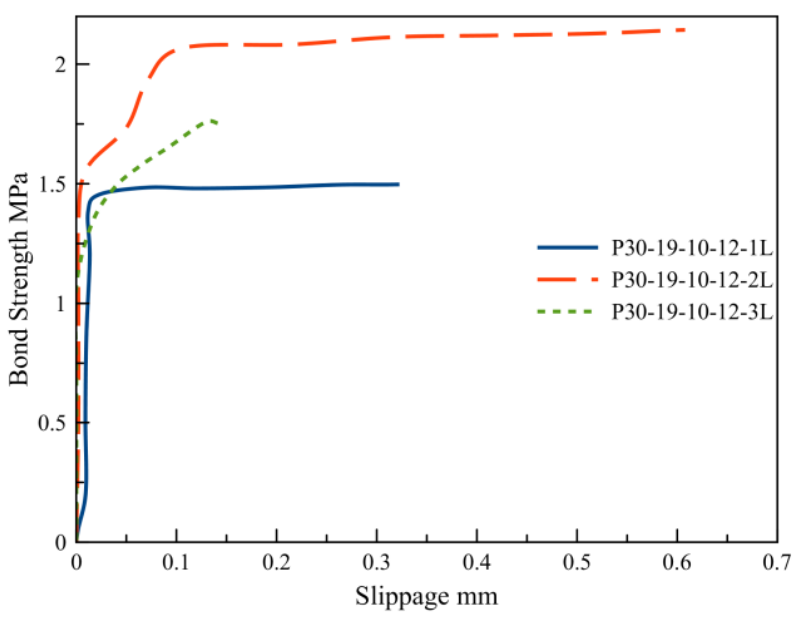

a. $\operatorname{Dmax}=19 \mathrm{~mm}$

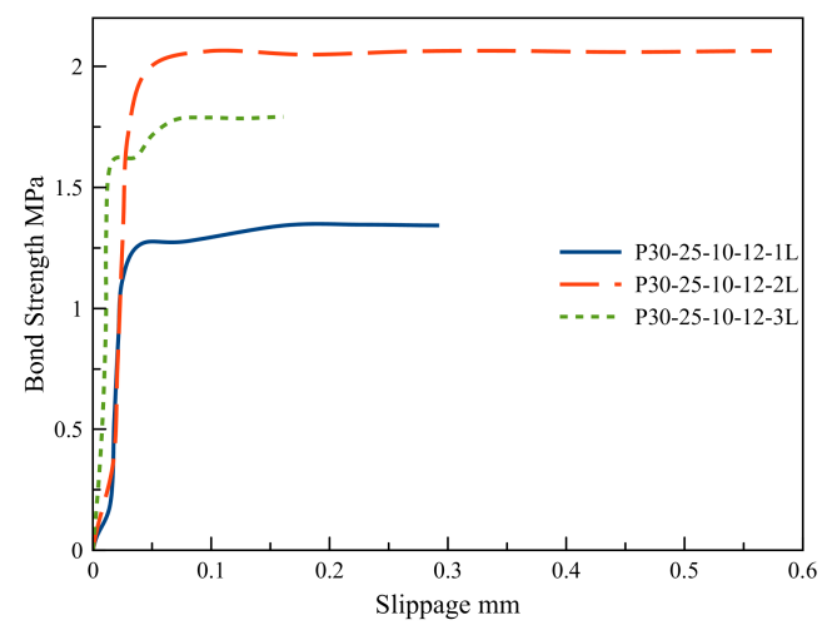

b. $D \max =25 \mathrm{~mm}$

Figure 3. Bond strength vs. slippage

After a certain number of layers, adding more layers increase the stress concentration between FRP and concrete which cause premature failure (de-bonding). In this case, de-bonding

happens at low load level when the number of layer is relatively high.

Fig. 4 show that the failure mode of specimens was interfacial de-bonding of the CFRP sheet accompanied with removing a thin layer from the concrete surface.

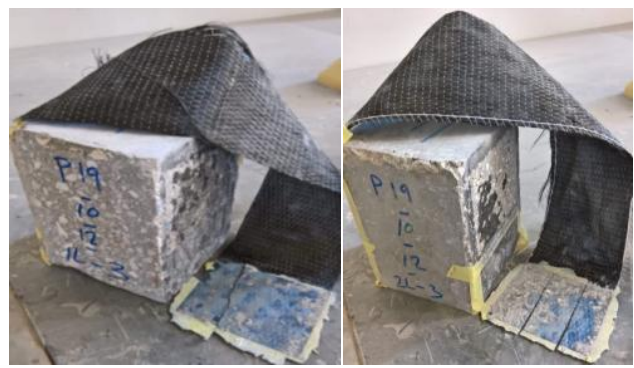

Figure 4. Failure modes.

\section{Conclusions}

This paper investigated the effect of number of CFRP sheet layers on the bond strength between CFRP sheet and concrete. Eighteen concrete prisms were strengthened using CFRP sheet and double-shear test was carried out to test the specimens. Three different layers layout and two maximum aggregate sizes were used. From the results, it can be concluded that:

1. The number of CFRP layers has significant effect on bond strength. The increase in number CFRP layers increases the bond strength beyond up to a certain value.

2. For both mixes, two layers of CFRP is the optimum number of layers that can be used to get the maximum bond strength.

3. The failure mode was de-bonding between the CFRP sheet and the concrete accompanied with separation of thin layer of concrete.

\section{References}

[1] Yao, J., Teng, J. G., Chen, J. F. "Experimental study on FRP to concrete bonded joints". Composites Part B: Engineering, 36(2), pp. 99-113. 2005

[2] Nakaba, K., Kanakubo, T., Furuta, T., Yoshizawa, H. "Bond Behavior between Fiber-Reinforced Polymer Laminates and Concrete". ACI Structural Journal, 98(3), pp. 359-367. 2001.

[3] Diab, Hesham M., and Omer A. Farghal. "Bond strength and effective bond length of FRP sheets/plates bonded to concrete considering the type of adhesive layer." Composites Part B: Engineering 58.618-624. 2014.

[4] Lorenzis, L. De., Miller, B., and Nanni, A.: Bond of Fiber-Reinforced Polymer Laminates to Concrete, ACI Material Journal, 98(3), 256-264, 2001.

[5] Nakaba, K., Kanakubo, T., Furuta, T., and Yoshizawa, H.: Bond Behavior between Fiber-Reinforced Polymer Laminates and Concrete, ACI Structural Journal, 98(3), 359-167. 2001. 
[6] Sato, Y., Asano, Y., and Ueda, T. : Fundamental Study on Bond Mechanism of Carbon Fiber Sheet, Concrete Library International, JSCE, No.37, June 2001, 97-115, 2000.

[7] Dai J. G., Sato Y., and Ueda, T.: Improving the Load Transfer and Effective Bond Length for FRP Composites Bonded to Concrete, Proceedings of the Japan Concrete Institute..24, 1423-1428, 2002

[8] Haddada R. H. and Al Dalou, A.A. "Experimental study on bond behavior between corrosion-cracked reinforced concrete and CFRP sheets." Journal of Adhesion Science and Technology, DOI: 10.1080/01694243.2017.1371912. 